\title{
Development and History of the Probability
}

\author{
Rohit A. Pandit, Shashim A. Waghmare, Pratiksha M. Bhagat \\ ${ }^{1}$ MS Economics, University of Wisconsin, Madison, USA \\ ${ }^{2}$ MS Economics, Texas A\&M University, College Station, USA \\ ${ }^{3}$ Bachelor of Engineering in Electronics \& Telecommunication, KITS Ramtek, India
}

\begin{abstract}
This paper is concerned with the development of the mathematical theory of probability, from its founding by Pascal and Fermat in an exchange of letters in 1654 to its early nineteenth-century apogee in the work of Laplace. It traces how the meaning of mathematics, and applications of the theory evolved over this period.
\end{abstract}

Keywords: Probability, game of chance, statistics

\section{Introduction}

The concepts of probability emerged before thousands of years, but the concrete inception of probability as a branch of Mathematics took mid-seventeenth century. In this era, the calculation of probabilities became quite noticeable though mathematicians remain foreign to the methods of calculation.

Chevalier de Mere, a nobleman, directed a simple question to his friend Blaise Pascal in the mid-seventeenth century which flickered the birth of Probability theory, as we know it today. This paper introduces the journey of Probability from its inception i.e. the classical approach to the applied probability in the strong mathematical sense i.e. the Measure Theory. We also dwelt upon the illustrations of how these theories were chiseled and forged into what we see today. Though it arose out of the study of gambling games but it has a range of applications extends beyond games into business decisions, insurance, law, medical tests, and the social sciences. This paper provides an informative perception towards the History and Development of Probability.

\section{History of Probability}

Gambling was popular and fashionable in French society in the seventeenth century. A gambler's dispute in 1654 led to the creation of a mathematical theory of probability by two famous French mathematicians, Blaise Pascal and Pierre de Fermat. Antoine Gombaud and Chevalier de Mere, French nobleman with an interest in gaming and gambling questions, called Pascal's attention to an apparent contradiction concerning a popular dice game. This problem and other posed by de Mere led to an exchange of letters between Pascal and Fermat in which the fundamental principles of probability theory were formulated for the first time.

Although a few special problems on games of chance had been solved by some Italian mathematicians in the $15^{\text {th }}$ and $16^{\text {th }}$ centuries, no general theory was developed before this famous correspondence. The Dutch scientist Christian Huygens, a Leibniz teacher, learned of this correspondence and shortly thereafter in 1657 published first book on probability; entitled De Ratiociniis in Ludo Aleae, it was a treatise on problems associated with gambling. Because of the inherent appeal of games of chance, probability theory soon became popular, and the subject developed rapidly during $18^{\text {th }}$ century.

The major contributors during this period were Jacob Bernoulli (1654-1705) and Abraham de Moivre (16671754).

Jacob (Jacques) Bernoulli was a Swiss mathematician who was the first to use the term integral. He was the first mathematician in the Bernoulli family, a family of famous scientists of the $18^{\text {th }}$ century. Jacob Bernoulli's most original work was ArsConjectandi published in Basel in 1713, eight years after his death. The work was incomplete at the time of his death but it was still a work of the greatest significance in the development of the theory of probability.

De Moivre was a French mathematician who lived most of his life in England. He pioneered the modern approach to the theory of probability, when he published The Doctrine of Chance: A method of calculating the probabilities of events in play in 1718. The definition of statistical independence appears in this book for the first time. The Doctrine of Chance appeared in new expanded editions in 1718, 1738 and 1756 . The birthday problem (in a slightly different form) appeared in the 1738 edition, the gambler's ruin problem in the 1756 edition. The 1756 edition of The Doctrine of Chance contained what is probably de Moivre's most significant contribution to probability

In 1812 Pierre de Laplace introduced host of new ideas and mathematical techniques in his book, TheorieAnalitique des Probabilities. Before Laplace, probability theory was solely concerned with developing a mathematical analysis of games of chance. Laplace applied probabilistic ideas to many scientific and practical problems. The theory of errors, actuarial mathematics, and statistical mechanics are examples of some of the important applications of probability theory developed in the $19^{\text {th }}$ century. Like so many other branches of mathematics the development of probability theory has been stimulated by the variety of its applications. 


\section{International Journal of Science and Research (IJSR) \\ ISSN (Online): 2319-7064}

Index Copernicus Value (2015): 78.96 | Impact Factor (2015): 6.391

\section{Development Over Period}

Fermat preferred to solve the problem by listing the ways the play might go. Suppose, for example, that Robin and Robert have staked equal money on being the first to win three points, and they want to stop the game and divide the stakes when Robin lacks two points and Robert lacks only one. Robert should get more than Robin because he is ahead but how much more? If two more games were to beplayed, there would be four possibilities:

Robert wins the first and the second.

Robert wins the first, and Robin wins the second. Robin wins the first, and Robert wins the second. Robin wins the first and the second.

In the first three cases, Robert wins the game (in the first two, it is not even necessary to play for the second point), and in the fourth case Robin wins the game. By Cardano's principle, the stakes should be in the same proportion: three for Robert and one for Robin. If the stakes are divided now, Robert gets three-fourths. Pascal preferred another method, the "method of expectations." This method relies on principles of equity instead of Cardano's principle, and it enabled Pascal to solve the problem when the players lack so many points that listing all the possibilities is impractical. Since the game is fair, Pascal said, both players have an equal right to expect to win the next point. If Robert wins it, he wins the whole stakes; this entitles him to half of 3 the stakes. If Robin wins, the two are tied; so both are entitled to half of what is left. So Robert is entitled to three-fourths altogether. Extending this backwards reasoning by mathematical induction, and using the recursive properties of what we now call Pascal's triangle, Pascal was able to solve the problem for any number of points the players might lack. He found, for example, that if Robin lacks four points and Robert lacks two, then their shares are found by adding the numbers in the base of the triangle in Figure 1: Robert's share is to Robin's as $1+5+10+10$ to $5+1$, or 13 to 3 .

\section{1 \\ 12345 \\ 13610 \\ 1410 \\ 15 \\ 1}

\section{Figure 1}

The combinatorial knowledge that underlay Pascal's reasoning was richer and less streamlined than the combinatorics now taught as a foundation for probability. Pascal organized much of this knowledge, together with his general solution of the problem of points, in his Traité $d u$ triangle arithmétique, which was published in 1665, three years after his death (Edwards 1987). Huygens heard about Pascal and Fermat's ideas but had to work out the details for himself. His treatise De ratiociniis in ludoaleae, published in 1657, essentially followed Pascal's method of expectations. In one respect, he went farther than Pascal. He justified the very idea that there was a fair price for a position in a game of chance by showing that by paying that price,the player would end up with the same chances for the same net payoffs that could be obtained in a fair game with side payments. At the end of his treatise, Huygens listed five problems about fair odds in games of chance, some of which had already been solved by Pascal and Fermat. These problems, together with similar questions inspired by other card and dice games popular at the time, set an agenda for research that continued for nearly a century. The most important landmarks of this work were James Bernoulli's Arsconjectandi, published in 1713, Montmort's Essaid'analyse sur les jeux de hasard, with editions in 1708 and 1711, and De Moivre'sDoctrine of Chances, with editions in 1718, 1738, and 1756. These authors investigated many of the problems still studied under the heading of discrete probability, including gambler's ruin, duration of play, handicaps, coincidences, and runs. In order to solve these problems, they improved Pascal and Fermat's combinatorial reasoning, summed infinite series, developed the method of inclusion and exclusion, and developed methods for solving the linear difference equations that arise from Pascal's method of expectations. Perhaps the most important technical mathematical development in this4 workwas the invention of generating functions. Though Laplace gave them their name much later, De Moivre invented them in 1733 in order to find the odds for different sums of the faces of a large number of dice. This was the first step in the development of what we now call Laplace and Fourier transforms.

From the time of Huygens onward there was one important practical application of this work: the pricing of annuities and life insurance policies. Huygens's ideas were first applied to pricing annuities by Jan de Witt in 1671 and Edmund Halley in 1694. De Moivre, in his Annuities on Lives, with editions in 1725, 1743, 1750, and 1752, and Simpson, in his Doctrine of Annuities and Reversions, published in 1742, extended this work to more complicated annuities, reversions, and insurance and assurance policies. This work involved the rate of interest, but otherwise it remained conceptually close to the work on games of chance.

\section{Background}

Probability has been developed by the contribution of many scientists and mathematicians, it is mentioned below:

\begin{tabular}{|l|l|}
\hline Before 1600 & $\begin{array}{l}\text { Cardano'sLiber de ludoaleaeattempts to calculate } \\
\text { probabilities of dice throws }\end{array}$ \\
\hline $17^{\text {th }}$ century & $\begin{array}{l}1654 \text { - Pascal and Fermat create mathematical } \\
\text { theory of probability } \\
1657 \text { - Huygens's De ratiociniis in ludoaleae first } \\
\text { book on mathematical probability }\end{array}$ \\
\hline $18^{\text {th }}$ century & $\begin{array}{l}1733 \text { - Abraham de Moivre introduces the normal } \\
\text { distribution to approximate the binomial } \\
\text { distribution probability } \\
1761 \text { - Thomas Bayes proves Bayes's theorem }\end{array}$ \\
\hline $19^{\text {th }}$ century & $\begin{array}{l}1814 \text { - Laplace's Essaiphilosophique sur les } \\
\text { probabilities defends a definition of probabilities in } \\
\text { terms of equally possible cases, introduces } \\
\text { generating functions and Laplace Transforms. } \\
1866 \text { - Venn's Logic of chance defends the } \\
\text { frequency interpretation of probability. }\end{array}$ \\
\hline
\end{tabular}




\section{International Journal of Science and Research (IJSR) \\ ISSN (Online): 2319-7064}

Index Copernicus Value (2015): 78.96 | Impact Factor (2015): 6.391

\section{References}

[1]Daston, Lorraine. Classical Probability in the Enlightenment. Princeton (Princeton University Press). 1988

[2] Hald, Anders 1990. A History of Probability and Statistics and their Applications before. New York (Wiley). 1750

[3] Kendall, Maurice G., and R. L. Plackett, eds. Studies in the History of Statistics and Probability. Volume 2. New York (Macmillan). 1977

[4] Todhunter, Isaac. A History of the Mathematical Theory of Probability. London (Macmillan). 1865

[5] Edwards, A.W.F. Pascal's Arithmetic Triangle. London (Griffin). 1987

[6] Dr. young Xu, History, Background and probability applications, 2012 